Research Article

\title{
Comparative efficacy of behavioral despair models in depicting antidepressant-like effect of tramadol
}

\author{
Amitabh A. Kumar ${ }^{1}$, Jayashree $D^{2}$, Sujith Tumkur Rajashekar ${ }^{1}$
}

\author{
${ }^{1}$ Department of Pharmacology, \\ Narayana Medical College, \\ Nellore-524002, Andhra \\ Pradesh, India \\ ${ }^{2}$ Department of Pharmacology, \\ Madha Medical College, \\ Chennai-600122, Tamil Nadu, \\ India
}

Received: 12 September 2013

Accepted: 21 September 2013

\section{*Correspondence to:}

Dr. Amitabh A. Kumar, Email: aks552914@gmail.com

(C) 2013 Kumar AA et al. This is an open-access article distributed under the terms of the Creative Commons Attribution Non-Commercial License, which permits unrestricted non-commercial use, distribution, and reproduction in any medium, provided the original work is properly cited.

\begin{abstract}
Background: Experimental evaluation of antidepressants (ADs) in diverse animal models is the need of time. There is a constant search for newer models with ease and rapid screening of $\mathrm{AD}$ activity. As earlier studies highlight $\mathrm{AD}$ effect of tramadol in animal models, the study was undertaken to compare antidepressant-like effect of tramadol in two models of behavioural despair in mice.

Methods: Tramadol was administered intraperitoneally (i.p.) at two different doses of 20 and $40 \mathrm{mg} / \mathrm{kg}$, once daily for 7 days to Swiss albino mice. The immobility period of control and drug-treated mice was recorded in tail suspension test (TST) and forced swim test (FST). The antidepressant (AD) effect of tramadol was compared with control (NS) and reference drug imipramine (10 mg/kg, p.o.), administered orally (p.o.) for seven successive days.

Results: Tramadol in tail suspension test (TST) produced significant antidepressant effect at 20 and $40 \mathrm{mg} / \mathrm{kg}$ doses, as depicted by reduction in immobility period of drug-treated mice compared to control group. The efficacy of tramadol at dose of $40 \mathrm{mg} / \mathrm{kg}$ was comparable to that of imipramine treated group $(\mathrm{p}<0.001)$.

Tramadol in forced swim test (FST) produced significant antidepressant effect only at the dose of $40 \mathrm{mg} / \mathrm{kg}$ as compared to control, while the results were insignificant as compared to imipramine treated group ( $\mathrm{p}>0.05)$.

Conclusion: The results of the present study depict antidepressant-like activity of tramadol in both the models of depression TST and FST. But TST in mice seems to be more efficacious in appraising the antidepressant like effect of tramadol.
\end{abstract}

Keywords: Antidepressant, Forced swim test (FST), Noradrenaline, Serotonin, Tail suspension test (TST), Tramadol

\section{INTRODUCTION}

Depression is an intricate malady with diverse pathology encompassing core symptoms such as feeling of misery and low self-worth which are not easily extrapolated in animal studies. ${ }^{1}$ Existing therapies for depression fail to generate absolute recovery and are associated with undesirable side effects, ${ }^{2,3}$ hence there is a great deal of unmet clinical need. However, development of innovative therapies require novel animal models or clever utilization of existing models, ${ }^{4,5}$ still there is a substantial necessity for a simple, economical, animal-friendly model with excellent predictive validity for rapid screening.

Behavioural despair test like forced swim test (FST) ${ }^{6}$ requires mice to swim in a confined space after an initial frantic effort to escape, animal later assumes an immobile posture. The test is one of the most popular screening tests for antidepressant (AD) activity. ${ }^{7}$ Another accepted model based on behavioural despair is tail suspension test (TST) ${ }^{8}$ In this model mice suspended by the tail displays initial rigorous struggle for escape followed by a period of immobility. In both the models, the state of immobility is coined as behavioural despair.

Tramadol, an opioid analgesic, used in the treatment of moderate to severe pain, mediates its analgesic efficacy ${ }^{9}$ through weak $\mu$ opioid receptor agonism, and inhibits the reuptake of noradrenaline (NA) and serotonin (5-HT). Both these mechanisms work in synergism to enhance the analgesic profile of tramadol. ${ }^{10}$ Numerous studies documented that central monoaminergic NA \& 5-HT 
reuptake inhibition mainly contributes to its analgesic effect instead of opioid pathway. ${ }^{11}$ Further, it has also been documented that tramadol predominantly inhibits reuptake of 5-HT in the raphe nucleus. ${ }^{12}$ ADs mainly act by inhibiting NA and 5-HT reuptake. These actions of tramadol possibly supplement for its antidepressant activity. Moreover, tramadol possesses a close structural resemblance with antidepressant venlafaxine and may share various pharmacological and molecular characteristics. $^{13}$ Many experimental studies reveal antidepressant-like effect of tramadol. ${ }^{9,14}$

Limited clinical studies support antidepressant action of tramadol, such as intramuscular administration of tramadol, was found to resolve suicidal ideation ${ }^{15}$ while tramadol monotherapy was found to be effective in refractory major depression cases. ${ }^{16}$

As there are a few and diverse studies comparing antidepressant profile of tramadol in various models of depression based on behavioural despair, so the present study was undertaken to evaluate the comparative effect of tramadol in TST and FST models of depression.

\section{METHODS}

\section{Animals}

Swiss albino mice weighing between 25-30 gm were used for this study. Mice were procured from central animal house of Narayana Medical College, Nellore. The animals were housed in cages in temperature-regulated rooms with air cooling and $12 \mathrm{~h}$ light and dark cycle, and had an access to food and water ad libitum. They were allowed to acclimatize to the laboratory conditions for a period of one week. The study was approved by the Institutional Animal Ethics Committee, Narayana Medical College (protocol number 14/2010/NMC) and all the experiments were performed as per the Committee for the purpose of control and supervision on experiments on animals (CPCSEA) guidelines.

\section{Drugs}

Test drug tramadol was sourced from Sigma Aldrich, Bengaluru, India, while reference drug imipramine was from Sun Pharma, Mumbai, India, dissolved in normal saline. All the chemicals and reagents used in the study were of analytical grade and were prepared fresh before test.

\section{Study design}

The animals were randomly divided into four groups containing six animals in each group $(n=6)$ for both the models (TST and FST). Group 1 was control group, pretreated with NS $(0.1 \mathrm{ml} / 10 \mathrm{~g})$, Group 2 and 3 were pretreated with two doses of tramadol 20 and $40 \mathrm{mg} / \mathrm{kg}$ (i.p.) respectively for 7 days (Table 1 and 2), Group 4 was pretreated with imipramine $10 \mathrm{mg} / \mathrm{kg}$ (p.o.) for 7 days.
Tramadol and imipramine were dissolved in NS. A pretest session was provided to all the animal groups 24 hour prior to the experimentation.

Table 1: Effect of tramadol on immobility period in tail suspension test (TST).

\begin{tabular}{|lll|}
\hline Groups & $\begin{array}{l}\text { Number } \\
\text { of Mice }\end{array}$ & $\begin{array}{l}\text { Duration of } \\
\text { immobility time } \\
\text { Mean(SD) }\end{array}$ \\
\hline 1. Control (NS) & 6 & $185.7(14.33)$ \\
\hline $\begin{array}{l}\text { 2. Tramadol 20 } \\
\text { mg/kg, i.p }\end{array}$ & 6 & $169(8.07)^{*}$ \\
\hline $\begin{array}{l}\text { 3. Tramadol } 40 \\
\text { mg/kg, i.p }\end{array}$ & 6 & $161.7(7.96)^{* *}$ \\
\hline $\begin{array}{l}\text { 4. Imipramine 10 } \\
\text { mg/kg, p.o. } \\
\text { (Standard) }\end{array}$ & 6 & $150.7(3.93)^{* * *}$ \\
\hline
\end{tabular}

ns- $\mathrm{p}>0.05, * * \mathrm{p}<0.01, * * * \mathrm{p}<0.001$

Table 2: Effect of tramadol on immobility period in forced swim test (FST).

\begin{tabular}{|c|c|c|}
\hline Groups & $\begin{array}{l}\text { Number } \\
\text { of Mice }\end{array}$ & $\begin{array}{l}\text { Duration of } \\
\text { immobility } \\
\text { time Mean(SD) }\end{array}$ \\
\hline 1. Control (NS) & 6 & $194.3(10.0)$ \\
\hline $\begin{array}{l}\text { 2. Tramadol } 20 \\
\mathrm{mg} / \mathrm{kg} \text {, i.p }\end{array}$ & 6 & $187.7(9.07)^{\mathrm{ns}}$ \\
\hline $\begin{array}{l}\text { 3. Tramadol } 40 \\
\mathrm{mg} / \mathrm{kg} \text {, i.p }\end{array}$ & 6 & $155(9.65)^{* * *}$ \\
\hline $\begin{array}{l}\text { 4. Imipramine } 10 \\
\mathrm{mg} / \mathrm{kg} \text {, p.o. } \\
\text { (Standard) }\end{array}$ & 6 & $137.8(9.96)^{* * *}$ \\
\hline
\end{tabular}

ns- $\mathrm{p}>0.05, * * \mathrm{p}<0.01, * * * \mathrm{p}<0.001$

\section{Behavioural despair models}

Tail suspension test $(\text { TST) })^{8}$

This animal model is based on the principle that when an animal is suspended upside down it displays characteristic behaviour of immobility after an initial period of mobility. The period of immobility reflects a state of depression which can be reduced by antidepressant drugs. ${ }^{17,18}$ Mice were suspended $50 \mathrm{~cm}$ above the floor by adhesive tape placed $1 \mathrm{~cm}$ from the tip of tail. Group 1 was treated with NS $(0.1 \mathrm{ml} / 10 \mathrm{~g})$, Group 2 and 3 were given tramadol in the doses of 20 and $40 \mathrm{mg}$ (i.p.) respectively, while Group 4 received imipramine 10 $\mathrm{mg} / \mathrm{kg}$ (p.o.) for 7 days. On the 7 th day animals were subjected to TST after 30 minute (i.p.) and 1 hour (p.o.) treatment respectively. Each mice was observed for a period of six minutes, initially mice showed vigorous struggling movement, then mice displayed alternating periods of immobility and vigorous struggling. The 
duration of immobility was recorded during the last 4 minute period, a mouse was considered immobile when it did not show any movement and hanged passively. Decrease in the duration of immobility period was considered as an index of antidepressant activity.

\section{Forced swim test (FST)}

This animal model is based on the principle that forcing mice to swim in restricted space from which they cannot escape leads to a characteristic behaviour of immobility. Such behaviour reflects a state of hopelessness, which can be treated by various drugs that are therapeutically effective in human depression. Mice were placed individually in glass chamber containing water. The test included, 6 min exposure of mice to the water container $(25 \times 12 \times 25 \mathrm{~cm})$ containing $15 \mathrm{~cm}$ of water maintained at $23-25^{\circ} \mathrm{C}$. Group 1 was treated with NS $(0.1 \mathrm{ml} / 10 \mathrm{~g})$, Group 2 and 3 were given tramadol in the doses of 20 and 40 mg (i.p.) respectively, while Group 4 received imipramine $10 \mathrm{mg} / \mathrm{kg}$ (p.o.) for 7 days. On the 7 th day animals were subjected to FST after 30 minute (i.p.) and 1 hour (p.o.) treatment respectively. Each mice was observed for a period of six minutes, a mouse was considered to be immobile when it floated or made only small movements necessary to keep its head above water. Decrease in the duration of immobility period was considered as an index of antidepressant activity.

\section{Statistical Analysis}

The data was reported in case record forms and entered into excel spreadsheet 2007. Statistical analysis was carried out using Microsoft Excel-2007 and Sigma Graph pad prism version-5 USA. Data was described as mean (Standard deviation). ${ }^{19}$ One way ANOVA followed by Post hoc Turkey's multiple Comparison tests was used for analysis of data between the four groups. For all inferential statistical tests a two tailed $(p<0.05)$ was considered significant.

\section{RESULTS}

In TST as per table 1 the immobility period with control (NS) as 185.7(14.33) sec whereas, it was 169(8.07) sec, 161.7(7.96) sec, and 150.7(3.93) sec with tramadol (20, $40 \mathrm{mg} / \mathrm{kg}$ ) and imipramine $10 \mathrm{mg} / \mathrm{kg}$ respectively. Tramadol $(20,40 \mathrm{mg} / \mathrm{kg})$ and imipramine treated groups showed significant reduction in immobility period as compared to control. Reduction in immobility period with tramadol $40 \mathrm{mg} / \mathrm{kg}(\mathrm{p}<0.001)$ was significantly higher as compared to tramadol $20 \mathrm{mg} / \mathrm{kg}(\mathrm{p}<0.05)$ suggesting its dose dependent $\mathrm{AD}$ activity. In this test, tramadol 20 $\mathrm{mg} / \mathrm{kg}$ shows significant reduction in immobility period as compared to control $(\mathrm{p}<0.05)$ (Figure 1$)$.

In FST as per table 2 the immobility period with control (NS) as 194.3(10.0) sec whereas, it was 187.7(9.07) sec, 155(9.65) sec, and 137.8(9.96) sec with tramadol (20, 40 $\mathrm{mg} / \mathrm{kg}$ ) and imipramine $10 \mathrm{mg} / \mathrm{kg}$ respectively. Reduction in the immobility period with tramadol $20 \mathrm{mg} / \mathrm{kg}$ was not significant as compared to control $(\mathrm{P}>0.05)$. Whereas, tramadol $40 \mathrm{mg} / \mathrm{kg}$ and imipramine treated groups showed significant reduction in immobility period as compared to control $(\mathrm{p}<0.001)$ (Figure 1).

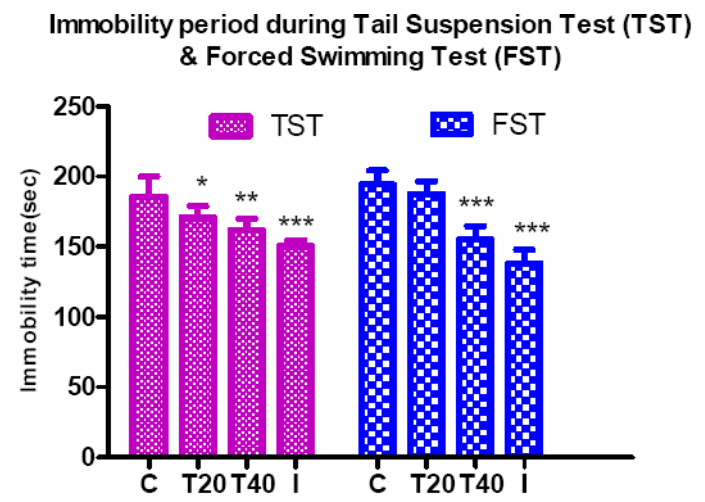

C- Control T20-Tramadol $20 \mathrm{mg} / \mathrm{kg}$ T40-Tramadol $40 \mathrm{mg} / \mathrm{kg} \quad$ I- Imipramine

\section{Figure 1: Immobility period in behavioural despair} models.

In TST tramadol $20 \mathrm{mg} / \mathrm{kg}$ shows significant reduction in immobility period as compared to control group $(\mathrm{p}<0.05)$.

In FST tramadol $20 \mathrm{mg} / \mathrm{kg}$ shows no significant reduction in immobility period as compared to control group $(\mathrm{p}>0.05)$.

\section{DISCUSSION}

Tail suspension test (TST) depicts the behavioural despair model professed to emulate a condition akin to human depression. TST wonderfully reveals the antiimmobility effect of a broad array of antidepressants, such as selective serotonin reuptake inhibitors (SSRI), tricyclic antidepressants (TCAs), atypical antidepressants, monoamine oxidase inhibitors (MAOI) and even electroconvulsive shock. ${ }^{20}$

The immobility exhibited by mice when exposed to unavoidable stress like forced swimming is considered to mirror a state of misery which is thought to display depressive disorders in humans and which are treated by antidepressant drugs. 8,21

The monoamine theory of depression suggests that depression is due to a dearth in one or another of the monoamine such as NA, 5-HT and or dopamine. ${ }^{22}$ Considering the monoamine postulation we conducted the study to evaluate and compare the antidepressant profile of tramadol in two models of depression TST and FST.

In our study we found that in TST, tramadol in the doses of $20(\mathrm{p}<0.05)$ and $40 \mathrm{mg} / \mathrm{kg}(\mathrm{p}<0.01)$ showed dosedependent antidepressant activity (Table 1, Figure 1). Whereas in FST tramadol $20 \mathrm{mg} / \mathrm{kg}$ showed no significant antidepressant activity as compared to control 
( $p>0.05$ ) (Table 2, Figure 1). The results of our study in TST are in accordance to the study conducted by Tayal et al., (2008). They reported that tramadol in the doses of 20 and $40 \mathrm{mg} / \mathrm{kg}$ showed antidepressant activity in TST model. $^{23}$

In earlier studies conducted by Rojas et al., (1998), they demonstrated dose dependent reduction in immobility period of tramadol treated group in $\mathrm{FST}^{9}$ which was significant at the higher dose of $40 \mathrm{mg} / \mathrm{kg} \quad(\mathrm{p}<0.05)$. These results are in accordance with our study as tramadol $20 \mathrm{mg} / \mathrm{kg}$ showed no significant antidepressant effect as compared to control ( $p>0.05)$ in FST (Table 2). Therefore from the results of our study we conclude that TST has better predictive validity in screening of antidepressant drugs in behavioural despair model as compared to FST. TST model seems to be animal and investigator friendly as depicted by St'eru et al., (1985). ${ }^{8}$ They documented that TST portray AD effect of drugs even at low doses. TST is specific for 5-HT uptake inhibitors, atypical antidepressants, MAOIs, TCA as compared to other models of behavioural despair.

A recent study carried out by Castagn'e, et al., (2010) describes numerous advantages of using TST such as no induction of hypothermia, the animals once taken out from the experimental set up recommence normal spontaneous activity instantly. ${ }^{24}$ As a result, no unusual post-experimental treatment such as rubbing or maintenance in a warmed setting is required. The test enhances comfort of the investigator. Additionally, the method can be automated, thereby permitting the testing of numerous animals simultaneously, with a resulting increase in output for screening purposes. An additional quality of the TST is that it exhibits a different gamut of pharmacological sensitivity than the FST, thus providing a sensitive and economical approach to the behavioural screening of antidepressants. A concluding benefit, shared with the mouse version of the FST, is its potential efficacy for studying transgenic animals.

\section{CONCLUSION}

The results of our study depict higher sensitivity of TST as compared to FST. The model has better predictive validity as antidepressant-like effect of tramadol was easily delineated in lower doses in TST model. Further, the model seems to be animal and investigator friendly and goes in accordance with good animal handling and laboratory practice so it should be positioned as a major screening procedure for evaluating antidepressant drugs. Nevertheless, these findings need to be substantiated by further experimental studies.

\section{ACKNOWLEDGEMENTS}

We would like to thank all the teaching and non-teaching staff of the Department of Pharmacology, Narayana Medical College, Nellore, A.P., India.
Funding: Nil

Conflict of interest: Not declared

Ethical approval: Approved by the Animal Ethics

Committee of Narayana Medical College

\section{REFERENCES}

1. Matthews K, Christmas D, Swan J, Sorell E. Animal models of depression: Navigating through the clinical fog. Neurosci. Biobehav. Rev. 2005; 29: 503-513.

2. Baghai TC, Volz HP, Moller HJ. Drug treatment of depression in the 2000s: An overview of achievements in the last 10 years and future possibilities. World J. Biol. Psychiatry. 2006; 7:198222.

3. Slattery DA, Hudson AL, Nutt DJ. Invited review: The evolution of antidepressant mechanisms. Fundam. Clin. Pharmacol. 2004; 18:1-21.

4. Bosker FJ, Westerink BH, Cremers TI, Gerrits M, van der Hart MG, Kuipers SD, van der Horst PG, den Boer JA, Korf J. Future antidepressants: what is in the pipeline and what is missing? CNS Drugs. 2004; 18:705-732.

5. Berton O, Nestler EJ. New approaches to antidepressant drug discovery: Beyond the monoanines. Nat. Rev. Neurosci. 2006; 7:137-151.

6. Porsolt RD, Le Pichon M, Jalfre M. Depression: A new animal model sensitive to antidepressant treatment. Nature. 1977; 266:730-732.

7. Castagn'e V, Porsolt RD, Moser P. Early behavioral screening for antidepressants and anxiolytics. Drug Dev. Res. 2006; 67:729-742.

8. St'eru L, Chermat R, Thierry B, Simon P. The tail suspension test: A new method for screening antidepressants in mice. Psychopharmacology. 1985; 85:367-370.

9. Rojas-Corrales MO, Gibert-Rahola J, Mico JA. Tramadol induces antidepressant-type effects in mice. Life Sci. 1998; 63:PL175-80.

10. Raffa RB, Friderichs E, Reimann W, Shank RP, Codd EE, Vaught JL, Jacoby HI, Selve N. Complementary and synergistic antinociceptive interaction between the enantiomers of tramadol. J Pharmacol Exp Ther. 1993; 267(1):331-40.

11. Desmeules JA, Piquet V, Collart L, Dayer P. Contribution of monoaminergic modulation to the analgesic effect of tramadol. Br J Clin Pharmacol. 1996; 41:7-12.

12. Sevcik J, Nieber K, Driessen B, Illes P. Effects of the central analgesic tramadol and its main metabolite, O-desmethyltramadol, on rat locus coeruleus neurones. Br J Pharmacol. 1993;110:16976.

13. Kiayias JA, Vlacchou ED, Lakka Papadodima E. Venlafaxime $\mathrm{HCl}$ in the treatment of painful peripheral diabetic neuropathy. Diabetes Care. 2000;23:699.

14. Rojas-Corrales MO, Berrocoso E, Gibert-Rahola J, Mico JA. Antidepressant-like effects of tramadol 
and other central analgesics with activity on monoamines reuptake, in helpless rats. Life Sci. 2002;72:143-52.

15. Spencer C. The efficacy of intramuscular tramadol as a rapid-onset antidepressant. Aust $\mathrm{N}$ Z Psychiatry. 2000; 34:1032-3.

16. Shapira NA, Verduin ML, Degraw JD. Treatment of refractory major depression with tramadol hydrochloride monotherapy. J Clin Psychol. 2001; 62:205-6.

17. Sunoh Kwon, Bombi Lee, Myunghwan Kim, Hyejung Lee, Hi-Joon Park, Dae-Hyun Hahm. Antidepressant-like effect of the methanolic extract from Bupleurum falcatum in the tail suspension test. Neuro-Psychopharmacol \& Biol Psychiat 2010;34:265-270.

18. Nadège Ripoll, Denis Joseph Paul David, Eric Dailly, Martine Hascoet, Michel Bourin. Antidepressant-like effects in various mice strains in the tail suspension test. Behavioural Brain Res 2003;143:193-200.

19. Curran-Everette D, Benos DJ. Guidelines for reporting statistics in journals published by the
American Physiological Society. Am J Physiol Regular Integr Comp Physiol 2004; 287:247-249.

20. Mahmoudi M, Ebrahimzadeh MA, Ansaroudi F, Nabavi SF, Nabavi SM. Antidepressant and antioxidant activities of Artemisia absinthium L. at flowering stage. Afr J Biotechnol. 2009;8:7170-5

21. Willner P. The validity of animal models of depression. Psychopharmacology (Berl) 1984;83:116.

22. Stahl SM. Psychopharmacology of antidepressants. London: Martin Dunitz Publisher; ISBN 1-85317513-7.

23. Tayal V, Singh BK and Chawla S. Evaluation of antidepressant activity of tramadol in mice. Ind $\mathrm{J}$ Pharmacol 2008; 40(3):129-130.

24. Castagn'e V, Moser, P, Roux S, Porsolt RD. Rodent Models of Depression: Forced Swim and Tail Suspension Behavioral Despair Tests in Rats and Mice. Current Protocols in Pharmacology. 2010; 49:5.8.1-5.8.14.

doi:10.5455/2319-2003.ijbcp20131217

Cite this article as: Kumar AA, D Jayashree,

Rajashekar ST. Comparative efficacy of behavioral despair models in depicting antidepressant-like effect of tramadol. Int J Basic Clin Pharmacol 2013;2:763-7. 